\title{
Effect of Chronic Administration of Selective Glucocorticoid Receptor Antagonists on the Rat Hypothalamic-Pituitary- Adrenocortical Axis
}

\author{
Cornelius G Bachmann', Astrid CE Linthorst', Florian Holsboer' and Johannes MHM Reul*,' \\ 'Max Planck Institute of Psychiatry, Section of Neuropsychopharmacology, Munich, Germany
}

\begin{abstract}
The effects of the selective glucocorticoid receptor (GR) antagonists ORG 34850, ORG 34II6, and ORG 345 I7 on the rat hypothalamic-pituitary-adrenocortical (HPA) system were investigated. To assess the potency of the compounds to occupy GR in the brain and pituitary, we applied a single acute subcutaneous (s.c.) injection ( $10 \mathrm{mg} / \mathrm{kg}$ ). ORG 34517 was most potent to occupy GR in the anterior pituitary and distinct brain areas, whereas all compounds were unable to occupy mineralocorticoid receptor (MR). Chronic administration of ORG 34850, ORG 34I I6, and ORG $34517(20 \mathrm{mg} / \mathrm{kg} /$ day $)$ for I, 3, and 5 weeks resulted only in minor changes in brain GR levels. However, profound increases of hippocampal MR were observed virtually at all time points. Treatment with ORG 34850 and ORG 34I 6 elicited episodic increases in HPA axis activity, whereas ORG 34517 did not cause any changes in HPA activity. Thus, the GR antagonists exert distinct effects on the HPA axis, which may be pertinent for the proposed antidepressant activity of these compounds.

Neuropsychopharmacology (2003) 28, I056-1067, advance online publication, 2 April 2003; doi:I 0. I038/sj.npp. I300I 58
\end{abstract}

Keywords: glucocorticoid receptor; mineralocorticoid receptor; HPA axis; major depression; antagonist; antidepressant drugs; steroids; stress

\section{INTRODUCTION}

Besides depressive psychopathology, patients suffering from major depression often have altered autonomic and neuroendocrine functioning. The system most commonly disturbed is the hypothalamic-pituitary-adrenocortical (HPA) axis (for a review see Holsboer, 2000). The control of HPA activity involves an autoregulatory feedback mechanism exerted by circulating corticosteroids via two different receptors (Reul and De Kloet, 1985; De Kloet and Reul, 1987): The mineralocorticoid receptor (MR) or Type I receptor shows a distinct distribution and is mainly expressed in the hippocampus (Gerlach and McEwen 1972; Reul and De Kloet, 1986; Van Eekelen et al, 1988; Herman et al, 1989; Reul et al, 2000) and pituitary gland (De Nicola et al, 1981; Moguilewsky and Raynaud, 1980; Reul and De Kloet, 1985, 1986; Reul et al, 1990). Glucocorticoid receptors (GRs) or Type II receptors are abundantly distributed in the brain and pituitary (De Kloet and McEwen, 1976; Rees et al, 1977; Fuxe et al, 1985; Reul

*Correspondence: JMHM Reul, Max Planck Institute of Psychiatry, Section of Neuropsychopharmacology, Kraepelinstrasse 2, D-80804 Munich, Germany, Tel: +498930622 443, Fax +498930622 371, E-mail: reul@mpipsykl.mpg.de

Received II June 2002; revised 24 October 2002; accepted 02 December 2002

Online publication: 19 December 2002 at http://www.acnp.org/ citations/Npp I 21902443 et al, 1990) with high levels in the hypothalamic PVN and in the hippocampal formation. MRs have a higher affinity for glucocorticoids $\left(K_{\mathrm{d}} \sim 0.2 \mathrm{~nm}\right)$, controlling basal HPA activity at low circulating glucocorticoid levels during the circadian trough of adrenocortical secretion (Reul and De Kloet, 1985; De Kloet and Reul, 1987; Reul et al, 2000). Elevated levels of glucocorticoids, present at the circadian peak or following stressful stimuli, exert their negative feedback action via lower affinity GRs $\left(K_{\mathrm{d}} \sim 2-5 \mathrm{~nm}\right.$ ) (De Kloet and Reul, 1987; Dallman et al, 1987; Reul et al, 2000). Therefore, a coordinated functioning of this dual receptor system, which allows for a dynamic regulation of the HPA axis, is necessary for maintaining homeostasis.

Typical observations among depressed patients with a hyperactive HPA axis are elevated amplitudes of cortisol secretory episodes (Linkowski et al, 1986; Sachar et al, 1973), an increased frequency of ACTH secretory episodes (Mortola et al, 1987), and several other aberrations at the different levels of this neuroendocrine system. Several studies on long-term antidepressant treatment suggest that clinical remission of depressive psychopathology is often preceded by normalization of HPA axis functioning (Holsboer et al, 1982; Heuser et al, 1990; HolsboerTrachsler et al, 1991). In line with these clinical findings are several preclinical studies on long-term antidepressant treatment in rats, which demonstrated that antidepressants, despite different primary neuropharmacological mechanisms, have the same restraining effect on HPA activity (Reul 
et al, 1993, 1994; Gesing and Reul, in preparation). Furthermore, these antidepressants increased the levels of hippocampal MR between 2 and 5 weeks of treatment, followed by moderate rises in GR level in the brain and pituitary. Other studies showed similar data (Kitayama et al, 1988; Brady et al, 1991, 1992). Reul et al (1993, 1994, 2000) have postulated that normalization of HPA disturbances might be a common denominator for the clinical efficiency of an antidepressive substance. Moreover, they hypothesized that an early increase in hippocampal MR levels might trigger a cascade of changes leading to normalization of HPA axis activity.

Since numerous clinical investigations point to hypercorticism as an important factor in the pathogenesis of depression, treating depression with GR antagonists or steroid synthesis inhibitors could be a promising strategy (Murphy et al, 1998; Wolkowitz et al, 1999; Belanoff et al, 2001; Reus and Wolkowitz, 2001). Administration of the GR antagonist RU 38486 clearly increased HPA axis drive in human subjects (Laue et al, 1989; Lamberts, 1991; Kawai et al, 1987) and rats (Lamberts et al, 1991; Van Haarst et al, 1996). However, application of RU 38486 as a GR antagonist is limited by its partial GR agonistic activity at the GR (Gruol and Altschmied, 1993; Havel et al, 1996) and its deficient receptor selectivity, as it also binds to progestin receptors (PRs) (Gagne et al, 1985). Lately, several highly selective GR antagonists have been developed as derivatives of RU 38486 (Peeters et al, 1998) asa possible treatment to restore normal HPA axis activity in disorders associated with cortisol hypersecretion, such as major depression. Corresponding to our hypothesis of increased hippocampal MR capacity as the initial phenomenon of successive changes in HPA axis activity during the course of antidepressant treatment (Reul et al, 1993, 1994, 2000), we intended to investigate the effects of the newly developed GR antagonists on brain corticosteroid receptor capacity and HPA axis activity of rats using a similar approach as the previous antidepressant studies. Therefore, we chose for a long-term treatment at moderate dosages similar to the applied antidepressant administration rather than demonstrating their pronounced GR antagonism by application of high dosages.

\section{MATERIALS AND METHODS}

\section{Animals}

Male Wistar rats (140-160g upon arrival; Charles River, Sulzfeld, Germany) were used for all experiments. They were housed in groups of three to six animals per cage under controlled conditions (constant temperature $22 \pm 1^{\circ} \mathrm{C}$; lights on from $6.00-20.00 \mathrm{~h} ; 40-60 \%$ humidity) with free access to food and water. Before the treatment was started, animals were allowed to adapt to the animal room for at least four days. All animal procedures were performed using protocols approved by the Ethical Committee on Animal Care and Use of the Government of Bavaria, Germany.

\section{Materials}

GR antagonists were a gift from NV Organon (Oss, The Netherlands). Polyethylene glycol and dimethylsulfoxide were purchased from Sigma (Deisenhofen, Germany), and aprotinine (Trasylol ${ }^{\mathbb{R}}$ ) from Bayer (Leverkusen, Germany).

\section{GR Antagonist Administration: Receptor Occupancy Study}

Receptor occupancy experiments were essentially conducted as described previously (Reul and De Kloet, 1985; Reul et al, 1989). To determine the potency of the GR antagonists to occupy corticosteroid receptors in vivo, 2day adrenalectomized rats received a single subcutaneous (s.c.) injection of GR antagonists (10 $\mathrm{mg} / \mathrm{kg}$ body weight). This dose was declared as the threshold dose for the penetration of the blood-brain barrier by NV Organon (Peeters et al, 1998). All compounds were dissolved in 5\% dimethylsulfoxide (DMSO)/polyethylene glycol-300 (PEG300). Control animals received the vehicle. At $1 \mathrm{~h}$ after injection, animals were anesthetized quickly in a glass jar containing saturated halothane (Hoechst, Frankfurt am Main, Germany) and decapitated immediately. Brain and pituitary were rapidly removed from the skull and dissected quickly. Tissues were frozen in liquid nitrogen and stored at $-80^{\circ} \mathrm{C}$. Measurement of binding to corticosteroid receptors was determined in $\left[{ }^{3} \mathrm{H}\right]$ steroid binding assays as described below. Receptor occupancy was determined by assessment of the residual MR and GR binding in tissues of GR antagonist treated rats as compared to receptor binding in vehicle-treated animals. The percentage difference between the receptor binding data was taken as the percentage occupancy.

\section{GR Antagonist Administration: Chronic Drug Treatment}

In choosing the route of drug administration, our objective was to save the animals from unspecific stress. Accordingly, similar to previous chronic antidepressant treatment experiments (Reul et al, 1993, 1994), the oral route was chosen for the chronic administration of the glucocorticoid antagonists. As all compounds showed a bad solubility in a drinkable liquid phase (eg ethanol $0.5 \% /$ water), application via the drinking water was impossible. Therefore, the drug was applied via the food (233 mg per $950 \mathrm{~g}$ food). The animals were treated for a period of maximum 5 weeks. Drug intake was monitored by weighing the food each time it was renewed (ie every third day). Based on the average food consumption per day, the drug concentration in the food and the average weight of the rats, a mean drug intake could be calculated (ie $20-25 \mathrm{mg} / \mathrm{kg} /$ day). Water intake was checked daily, body weight gain was determined once a week.

\section{Surgery, Tissue Collection, and $\left[{ }^{3} \mathrm{H}\right]$ Steroid Binding Assay}

For corticosteroid binding measurement, treatment was terminated two days before decapitation and bilateral adrenalectomy was performed under halothane anesthesia to deplete their bodies of endogenous corticosteroids and GR antagonists. After surgery, the animals were maintained on $0.9 \% \mathrm{NaCl}$ in drinking water and rat chow without drug. Immediately after removal from the body, adrenal glands 
were placed in an Eppendorf tube (adrenals of one rat per tube) and kept on normal ice. The weight of the carefully cleaned adrenals was determined on the same day as the day of surgery to prevent unreliable adrenal weight data because of water loss from the frozen tissue during long-term storage. In addition, the rats were weighed at the time of adrenalectomy.

At 2 days after adrenalectomy, the rats were quickly $(<20 \mathrm{~s})$ anesthetized with halothane in a glass jar and killed by decapitation. Trunk blood was collected in ice-chilled EDTA-coated tubes, and the plasma was checked for the absence of any endogenous corticosterone by RIA (ICN Biomedicals, Costa Mesa, USA). Thymuses were removed, cleaned and weighed on the same day. Immediately after decapitation, the brain and the pituitary were rapidly removed from the skull. Subsequently, the anterior part of the pituitary was separated from the neurointermediate lobe, and the hippocampus, hypothalamus, amygdala, frontal cortex, and neocortex (consisting of parietal, cingular, and entorhinal cortex) were dissected from the brain. Dissected tissues were instantaneously frozen in liquid nitrogen and stored at $-80^{\circ} \mathrm{C}$ until corticosteroid receptor binding assay.

The MR and GR binding assay was conducted as described (Reul et al, 1993; Gesing et al, 2001). Pooled tissues of six rats per group were homogenized $(100 \mathrm{mg}$ brain tissue/ml; $50 \mathrm{mg}$ anterior pituitary tissue/ml; 10 strokes at $900 \mathrm{rpm})$ in ice-cold $5 \mathrm{mM}$ Tris- $\mathrm{HCl}(\mathrm{pH} 7.4)$ containing $5 \%$ glycerol, $10 \mathrm{mM}$ sodium molybdate, $1 \mathrm{mM}$ EDTA, and $2 \mathrm{mM} \beta$-mercaptoethanol using a glass homogenizer with a Teflon pestle milled at a clearance of $0.25 \mathrm{~mm}$ on the radius. The homogenate was centrifuged at $100000 \mathrm{~g}$ for $60 \mathrm{~min}$ at $0-2^{\circ} \mathrm{C}$ to obtain cytosol (ie supernatant fraction). All reagents used were of analytical grade. Aliquots of cytosol $(100 \mu \mathrm{l})$ were incubated with $\left[{ }^{3} \mathrm{H}\right]$ steroids over a concentration range of $0.1-10 \mathrm{nM}(6-8$ concentrations; total volume $150 \mu \mathrm{l})$. In some experiments, steroid receptors were measured with one saturating concentration of $\left[{ }^{3} \mathrm{H}\right]$ steroid $(10 \mathrm{nM},>90 \%$ saturation of binding) in five- to seven-fold. Total binding to soluble macromolecules was determined with $\left[{ }^{3} \mathrm{H}\right]$ aldosterone (87$94 \mathrm{Ci} / \mathrm{mmol}$ NEN DuPont, Dreieich, Germany) or with $\left[{ }^{3} \mathrm{H}\right]$ dexamethasone $\quad(85-106 \mathrm{Ci} / \mathrm{mmol}$, Amersham, Braunschweig, Germany). For measurement of MR, total binding was assessed by incubating cytosol with $\left[{ }^{3} \mathrm{H}\right]$ aldosterone in the presence of a 100-fold excess of the specific glucocorticoid agonist RU 28362 (11 $\beta, 17 \beta$-dihydroxy-6methyl-17 $\alpha$-(1-propionyl)androsta-1,4,6-triene-3-one). Unlabeled RU 28362 was included to prevent $\left[{ }^{3} \mathrm{H}\right]$ aldosterone from binding to GR, so that only binding of this $\left[{ }^{3} \mathrm{H}\right]$ ligand to MR was measured. Nonspecific binding was determined in parallel incubations containing a 1000-fold excess of corticosterone in addition to cytosol and $\left[{ }^{3} \mathrm{H}\right]$ aldosterone. Total binding for the GR was determined by incubating cytosol with $\left[{ }^{3} \mathrm{H}\right]$ dexamethasone. Since $\left[{ }^{3} \mathrm{H}\right]$ dexamethasone also displays considerable affinity (at least in vitro) for MR (Reul et al, 2000), the fraction of $\left[{ }^{3} \mathrm{H}\right]$ dexamethasone binding to MR was estimated by including a 100-fold excess of RU 28362 in parallel incubation tubes. Nonspecific binding was determined in parallel incubations containing a 1000 -fold excess of dexamethasone in addition to cytosol and $\left[{ }^{3} \mathrm{H}\right]$ dexamethasone.
After incubation for $20-24 \mathrm{~h}$ at $0^{\circ} \mathrm{C}$, bound and free $\left[{ }^{3} \mathrm{H}\right]$ steroid were separated by Sephadex LH-20 (Pharmacia, Uppsala, Sweden) gel filtration ( $100 \mu \mathrm{l}$ of the cytosol-steroid mixture was applied to the LH-20 columns), and radioactvity was measured in a liquid scintillation counter. The protein concentration was determined by the method of Lowry et al (1951) with BSA as the standard. The binding data were expressed as femtomoles per milligram protein (fmol/mg) and nonspecific binding was substracted from total binding to yield specific binding. In this manner, the MR concentration could be measured directly. However, GR binding was estimated by substraction of the specific binding of $\left[{ }^{3} \mathrm{H}\right]$ dexamethasone $+100 \times \mathrm{RU} 28362$ from the specific binding of $\left[{ }^{3} \mathrm{H}\right]$ dexamethasone. $\left[{ }^{3} \mathrm{H}\right]$ dexamethasone $+100 \times \mathrm{RU} 28362$ rather than $\left[{ }^{3} \mathrm{H}\right]$ aldosterone $+100 \times$ RU 28362 binding data were used to estimate the amount of the specific $\left[{ }^{3} \mathrm{H}\right]$ dexamethasone binding to $\mathrm{MR}$, because $\left[{ }^{3} \mathrm{H}\right]$ dexamethasone $+100 \times \mathrm{RU} 28362$ binding to MR was found to be about $30 \%$ less than $\left[{ }^{3} \mathrm{H}\right]$ aldosterone $+100 \times \mathrm{RU} 28362$ binding to this receptor type (Reul et al, 2000).

The maximal number of binding sites $\left(B_{\max }\right)$ and relative binding affinity $\left(K_{\mathrm{d}}\right)$ were determined by Scatchard analysis.

\section{Neuroendocrine Experiments}

All experiments and surgical procedures were performed between 7.00 and $11.00 \mathrm{am}$. Great effort was undertaken to keep the rats undisturbed during the day before the experiment. On the day of the experiment, rats were killed either under basal early morning conditions or $15 \mathrm{~min}$ after onset of forced swim stress. The forced swimming procedure was carried out similar to the Porsolt protocol (Porsolt et al, 1978). Briefly, the rats were placed for $15 \mathrm{~min}$ in glass cylinders (height $35 \mathrm{~cm}$, diameter $24 \mathrm{~cm}$ ) containing water to a height of $20 \mathrm{~cm}$ and at $25^{\circ} \mathrm{C}$. Immediately thereafter rats were rapidly anesthetized in a glass jar containing saturated halothane $(<20 \mathrm{~s}$; Hoechst, Frankfurt am, Germany) and decapitated immediately. Brain and pituitary were rapidly removed from the skull and frozen in isopentane $\left(-40^{\circ} \mathrm{C}\right)$ and on dry ice. Trunk blood was collected in prechilled EDTA-coated tubes containing Trasylol (Bayer, Leverkusen, Germany). Plasma was prepared by centrifugation $\left(3000 \mathrm{rpm}, 4^{\circ} \mathrm{C}, 20 \mathrm{~min}\right)$ and stored at $-80^{\circ} \mathrm{C}$. Adrenal glands and thymuses were removed from the body and treated as described.

\section{Measurement of Plasma ACTH and Corticosterone}

Plasma ACTH and corticosterone concentrations were measured using commercially available radioimmunoassay kits (ICN Biomedicals, Costa Mesa, USA). The inter- and intra-assay coefficients of variability for ACTH were 7 and $5 \%$ with a detection limit of $2 \mathrm{pg} / \mathrm{ml}$. For corticosterone, the inter- and intra-assay coefficients were 7 and $4 \%$, respectively, with a detection limit of $1.5 \mathrm{ng} / \mathrm{ml}$.

\section{Statistical Analysis}

Results are presented as means \pm SEM. Assessment of statistically significant differences between the groups of 
time course experiments on physical parameters (body weight, adrenal weight, and thymus weight), receptor binding measurements, and plasma hormone concentrations was performed with two-way analysis of variance (ANOVA). Since RU 38486 treatment was only conducted for 3 weeks, these data were omitted from the two-way ANOVA. However, to assess the statistical significance of the effect of RU 38486 treatment, the data were included in the one-way ANOVA analysis of the 3-week time-point data. Data obtained from acute antagonist treatment experiments were tested with one-way ANOVA. In appropriate cases, ANOVA was followed by a post hoc Dunnett's test. Values of $p<0.05$ were considered to indicate significant difference if compared with the control group.

\section{RESULTS}

\section{Chemical Structures}

Figure 1 shows the chemical structures of the compounds Org 34517, Org 34850, Org 34116 and RU 38486. These graphs illustrate the chemical relation between the different molecules.

\section{Occupancy of Brain and Anterior Pituitary Corticosteroid Receptors by GR Antagonists}

Occupancy of corticosteroid receptors by GR antagonists was determined in various brain areas and in the pituitary. Figure 2 shows that there were marked differences between the GR antagonists in their efficacy to occupy GRs, not only among the compounds but also among the tested tissues. ORG 34517 clearly showed the highest potency in binding to brain and anterior pituitary GRs, because binding of $\left[{ }^{3} \mathrm{H}\right]$ dexamethasone to GR was most substantially reduced in animals treated with this antagonist. As compared to the binding of ORG 34517 to GRs, that of ORG 34850 and ORG 34116 showed much less potency and was very much dependent of the tissue. ORG 34850, at least at the used dose, was unable to occupy GRs in the hippocampus, amygdala, and neocortex, whereas GR occupancy in the hypothalamus, frontal cortex, and anterior pituitary was moderate to high (Figure 2). ORG 34116 did not occupy GRs in the hippocampus and showed low to moderate occupancy levels in all other tissues (Figure 2). Overall, for all ligands the anterior pituitary GRs presented the highest occupancy levels of all tissues (Figure 2). No occupancy of MR by GR antagonists was observed (data not shown).

\section{Time Course of Physical Parameters}

Over the 5 weeks course of treatment an overall significant increase in body weight and adrenal weight (two-way ANOVA) was observed, whereas thymus weight significantly decreased (two-way ANOVA). Oral administration of the GR antagonists did not result in any significant differences in body weight at the respective time points, except for the RU 38486 treatment of 3 weeks that resulted in a small, but significant, reduction in body weight (Figure 3a). Adrenal weight ( $=$ weight per 2 adrenals) of animals treated with ORG 34850 and ORG 34116 was significantly increased after 1, 3, and 5 weeks of treatment (Figure $3 \mathrm{~b}$ ). Application of ORG 34517 and RU 38486 yielded no significant changes in adrenal weight. The thymus weight was markedly elevated after 1 and 3 weeks of treatment with ORG 34116, as it was after a 3-week administration of ORG 34850 in comparison with the respective control groups (Figure 3c). Administration of ORG 34517 did not change thymus weight at any time. RU 38486 treatment for 3 weeks resulted in a significant reduction of thymus weight.

\section{Effect of Chronic Treatment with GR Antagonists on Hippocampal Corticosteroid Receptors}

Measurement of hippocampal MR levels revealed marked time-dependent and GR-antagonist-specific increases at all

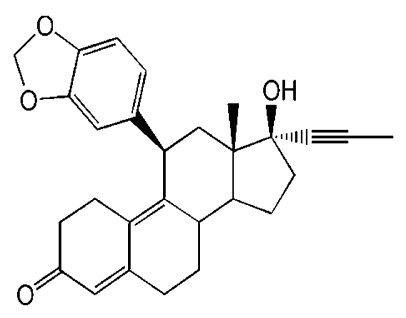

ORG 34517

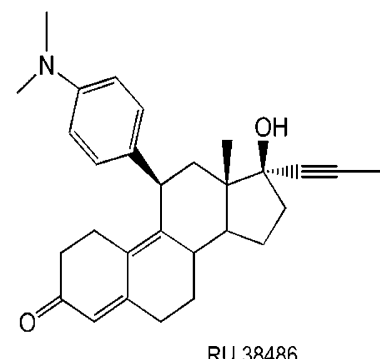

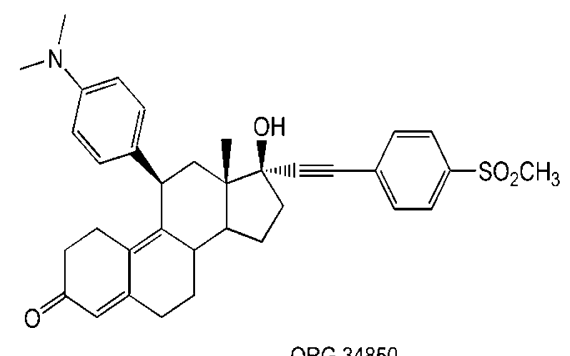

ORG 34850

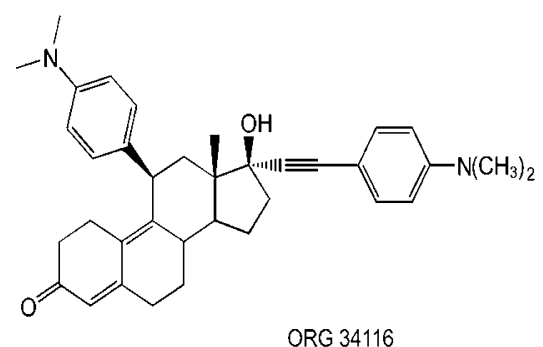

Figure I Chemical structures of the compounds Org 34517, Org 34850, Org 34116, and RU 38486. 
1060
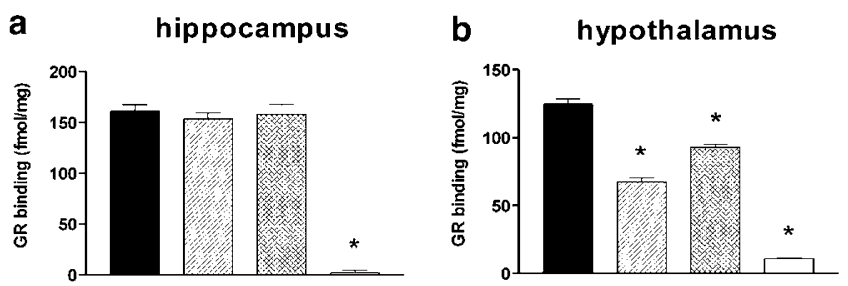

C

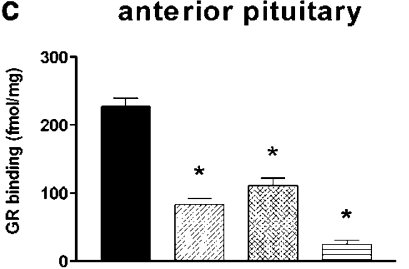

e

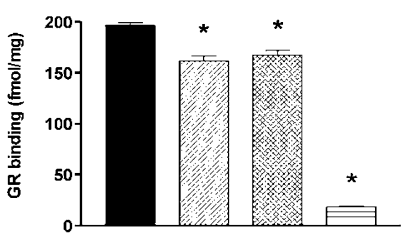

CONTROL

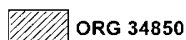

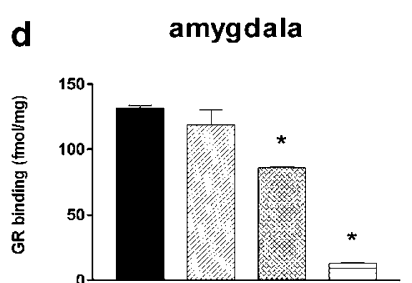

$f$

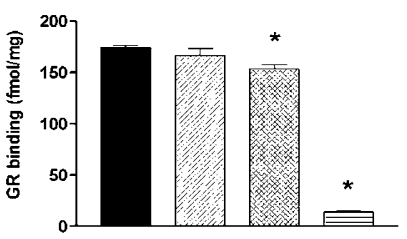

ORG 34116

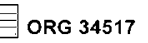

Figure 2 Occupancy of corticosteroid receptors by GR antagonists Effect of acute administration of antagonists on binding of $\left.{ }^{3} \mathrm{H}\right]$ dexamethasone to GR in the anterior pituitary and distinct brain regions. Rats (six per group) received a single s.c. injection of either GR antagonists $(10 \mathrm{mg} / \mathrm{kg})$ or 5\% DMSO/PEG (control) and were decapitated I h thereafter. Measurements of GR and MR concentrations, expressed as femtomoles per mg protein (mean \pm SEM), were performed at a single concentration of $\left.{ }^{3} \mathrm{H}\right]$ steroid ( $10 \mathrm{nM},>90 \%$ saturation). No effect on binding of $\left.{ }^{3} \mathrm{H}\right]$ aldosterone to $\mathrm{MR}$ was obtained (data not shown). One-way ANOVA: hippocampus-GR (effect of treatment), $F(3.16)=130.708$, $p<0.0005$; anterior pituitary-GR: effect of treatment: $F(3.16)=75.926$, $p<0.0005$; hypothalamus-GR (effect of treatment), $F(3.16)=346.205$, $p<0.0005 ;$ amygdala-GR (effect of treatment), $F(3.16)=85.723$, $p<0.0005$; neocortex-GR (effect of treatment), $F(3.16)=337.714$, $p<0.0005$; frontal cortex-GR (effect of treatment), $F(3.16)=480.004$, $p<0.0005$; * $p<0.05$ (vs the control group, post hoc Dunnett's t-test).

times during the course of the treatment (Figure 4a). As compared to the controls, the MR concentration in ORG 34116-treated rats was elevated after $1(+26 \%), 3(+52 \%)$, and 5 weeks $(+24 \%)$. Administration of ORG 34850 resulted in statistically significant rises in hippocampal MR levels after $1(+50 \%)$ and $5(+16 \%)$ weeks, whereas hippocampal MR levels determined in animals treated with ORG 34517 were only elevated after 3 weeks $(+41 \%)$. A pronounced increase $(+61 \%)$ in hippocampal MR levels was observed in animals treated with RU 38486 for 3 weeks (Figure 4a).

Regarding the effects on hippocampal GRs, significant changes (ie decreases) were only observed after the administration of ORG 34116 (Figure 4b). Data obtained from Scatchard analyses yielded no changes in $K_{\mathrm{d}}$ values of $\mathrm{MR}$ and GR binding during the course of the treatment $\left(K_{\mathrm{d}}\right.$ values for $\left[{ }^{3} \mathrm{H}\right]$ aldosterone binding to $\mathrm{MR}$ and $\left[{ }^{3} \mathrm{H}\right] \mathrm{dex}-$ amethasone binding to GR were $0.09-0.15$ and $1.2-1.5 \mathrm{nM}$, respectively).
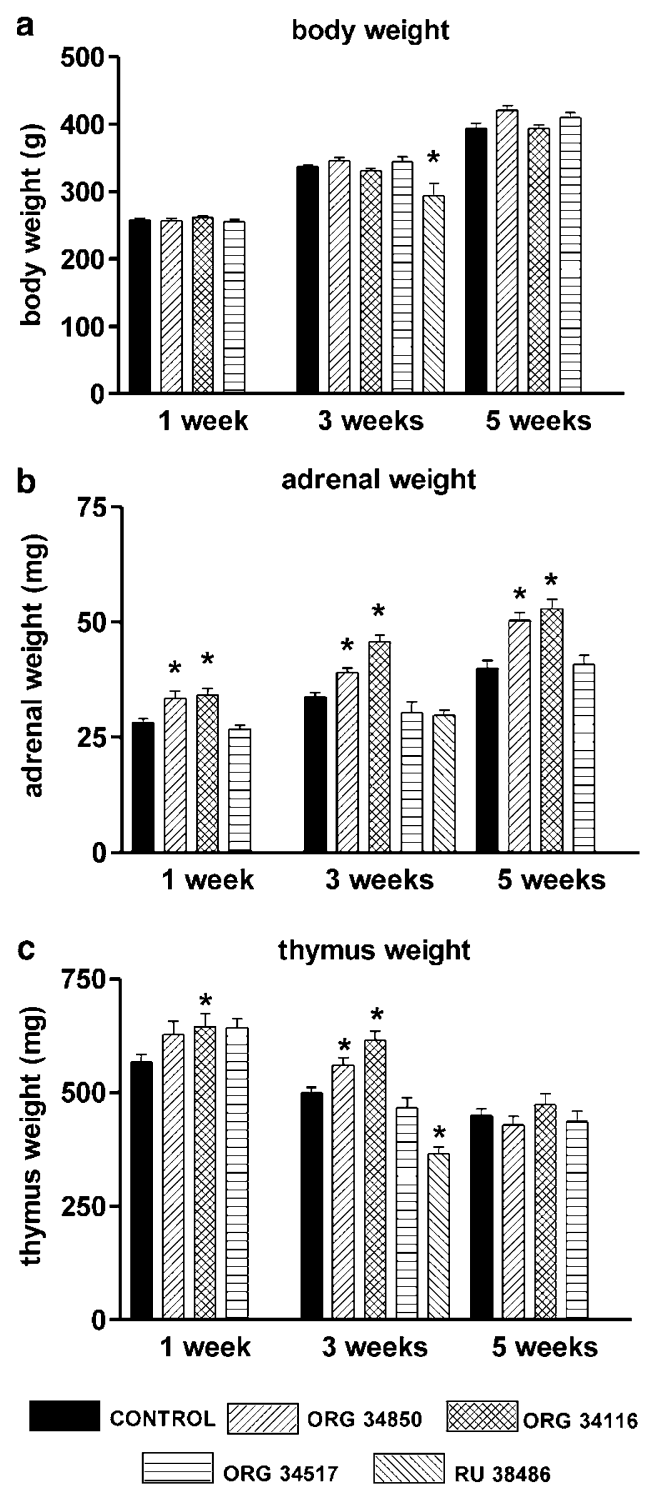

Figure 3 Time course of the effect of chronic GR antagonist administration on body weight (a), adrenal weight (b), and thymus weight (c). The data on the adrenal weights were expressed as the weight per 2 adrenals in milligram (mean \pm SEM). Rats (15-60 per group) received either GR antagonists (233 $\mathrm{mg}$ per $950 \mathrm{~g}$ food: $25 \mathrm{mg} / \mathrm{kg} /$ day) or food (control, black bar). The animals were killed after 1, 3, and 5 weeks of treatment. Adrenalectomy was conducted 2 days before decapitation, and treatment was stopped at the same time. Two-way ANOVA: body weight: effect of duration, $F(2.333)=673.19, p<0.0005$; effect of treatment, $F(3.333)=4.80, p<0.01$; effect by interaction of duration and treatment, $F(6.333)=2.59, \quad p<0.02 ; \quad$ adrenal weight: effect of duration, $F(2.3333)=91.890, p<0.0005$; effect of treatment, $F(3.333)=39.716$, $p<0.0005$; effect by interaction of duration and treatment, $F(6.333)=1.914, \quad p>0.05$; thymus weight: effect of duration, $F(2.3333)=63.686, p<0.0005$; effect of treatment, $F(3.333)=7.815$, $p<0.0005$; effect by interaction of duration and treatment, $F(6.333)=3.343, p<0.0$ I; post hoc Dunnett's $t$-test; $* p<0.05$ (vs the control group).

\section{Effect of Chronic Treatment with GR Antagonists on Corticosteroid Receptors: Neuroanatomical Specifity}

Chronic administration of GR antagonists generated timedependent changes in corticosteroid receptor concentrations in distinct brain and pituitary tissues. Oral application 
a hippocampal MR concentration
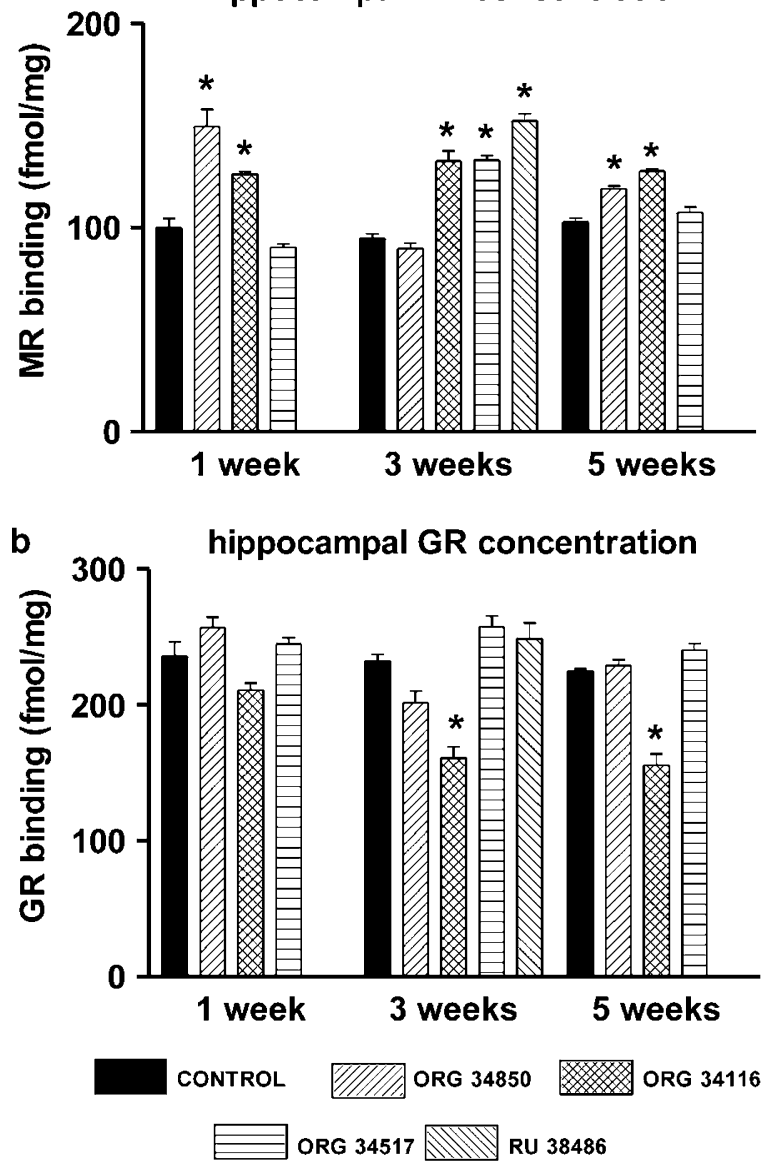

Figure 4 Time course of the effect of GR antagonist treatment on MR (a) and GR (b) concentrations in the rat hippocampus. Rats (5-7 per group) were treated with GR antagonists, including RU 38486, adrenalectomized and decapitated as outlined in the legend to Figure 3. Hippocampal MR and GR, expressed as femtomoles per mg protein (mean \pm SEM), were measured by radioligand binding assay (see Materials and methods). Two-way ANOVA: MR: effect of duration, $F(2.52)=0.465$, $p>0.05$ (nonsignificant); effect of treatment, $F(4.52)=56.056, p<0.0005$, effect by interaction of duration and treatment, $F(6.52)=37.787$, $p<0.0005$; GR: effect of duration, $F(2.52)=14.334$, $p<0.0005$; effect of treatment, $F(4.52)=44.797, p<0.0005$; effect by interaction of duration and treatment, $F(6.52)=6.229, p<0.0005$; post hoc Dunnett's $t$-test; $* p<0.05$ (vs the control group).

of ORG 34850 caused only small, mostly statistically insignificant changes of MR and GR levels in all tested regions (Figure 5), except for a marked MR and GR downregulation in the neocortex after 1 week of treatment (Figure $5 \mathrm{e}, \mathrm{f}$ ).

In ORG 34116-treated rats, anterior hypophyseal MR concentrations were profoundly downregulated only at 1 week, while overall brain MR levels were found to be elevated, reaching statistical significance at 1 and 3 weeks in the amygdala and neocortex, and at 3 weeks in the frontal cortex. Brain and pituitary GR binding levels were profoundly reduced in animals treated with ORG 34116 (Figure 5), albeit different time courses were observed. GR levels in pituitary and hypothalamus were already downregulated after 1 week of treatment, whereas for the other brain structures including hippocampus (see Figure $4 \mathrm{~b}$ ) this took at least 3 weeks of treatment.
In the pituitary, neocortex, and frontal cortex transient rises in MR levels were observed in animals treated with ORG 34517 with a statistically significant MR upregulation at 3 weeks. At 1 week, a marked downregulation in amygdaloid and neocortical MR concentration was found. Only minor effects were measured in the brain and pituitary GR levels after chronic administration of ORG 34517 (Figure 5).

RU 38486 was administered for 3 weeks and caused a marked increase in MR concentration in the amygdala and frontal cortex. GR numbers were increased in the amygdala and frontal cortex, but significantly reduced in the hypothalamus. Determination of hypophyseal GR concentration after chronic application of RU 38486 was impossible because of loss of tissue.

Data obtained from Scatchard analyses yielded no changes in $K_{\mathrm{d}}$ values of MR and GR binding during the course of the treatment in any of the measured tissues $\left(K_{\mathrm{d}}\right.$ values for $\left[{ }^{3} \mathrm{H}\right]$ aldosterone binding to $\mathrm{MR}$ and $\left[{ }^{3} \mathrm{H}\right] \mathrm{dex}-$ amethasone binding to GR were $0.09-0.15$ and $1.2-1.5 \mathrm{nM}$, respectively).

\section{Effect of Chronic Treatment with GR Antagonists on HPA Hormones}

Since the changes observed in the brain and pituitary MR and GR concentrations and adrenal weight might be related to alterations in HPA functioning, basal and stress-induced ACTH and corticosterone plasma levels were measured (Figure 6). Basal corticosterone levels were below or slightly over the detection limit. Baseline plasma ACTH levels were unchanged except for a significant rise at 5 weeks in ORG 34850-treated rats (Figure 6a). Chronic treatment with ORG 34850 for 5 weeks resulted in elevated basal plasma ACTH levels. The stress-induced plasma corticosterone response to forced swim stress was enhanced in 5 weeks ORG 34850 and ORG 34116 treated rats. The poststress plasma ACTH response was attenuated after 3 weeks in ORG 34850-treated rats.

\section{DISCUSSION}

The present report shows that administration of the selective GR antagonists ORG 34850, ORG 34116, and ORG 34517 causes significant changes in the various components of the HPA axis, involving corticosteroid receptors in distinct regions of the brain and pituitary, the adrenal gland, and secretion of ACTH and corticosterone. In particular, this study indicates that chronic oral application of the selective GR antagonists to rats results in a time-dependent enhancement of hippocampal MR capacity, which corresponds with our previous observations, showing an enhanced hippocampal MR capacity during chronic application of different antidepressants to rats (Reul et al, 1993, 1994; Gesing and Reul, in preparation).

Our present data corroborate that the substances have a distinct potency to occupy brain and pituitary GR. All compounds were synthesized as derivatives of RU 38486 and display a higher GR selectivity because of a significant reduction in PR binding (Peeters et al, 1998). A single s.c. injection of the three GR antagonists $(10 \mathrm{mg} / \mathrm{kg}$ body 

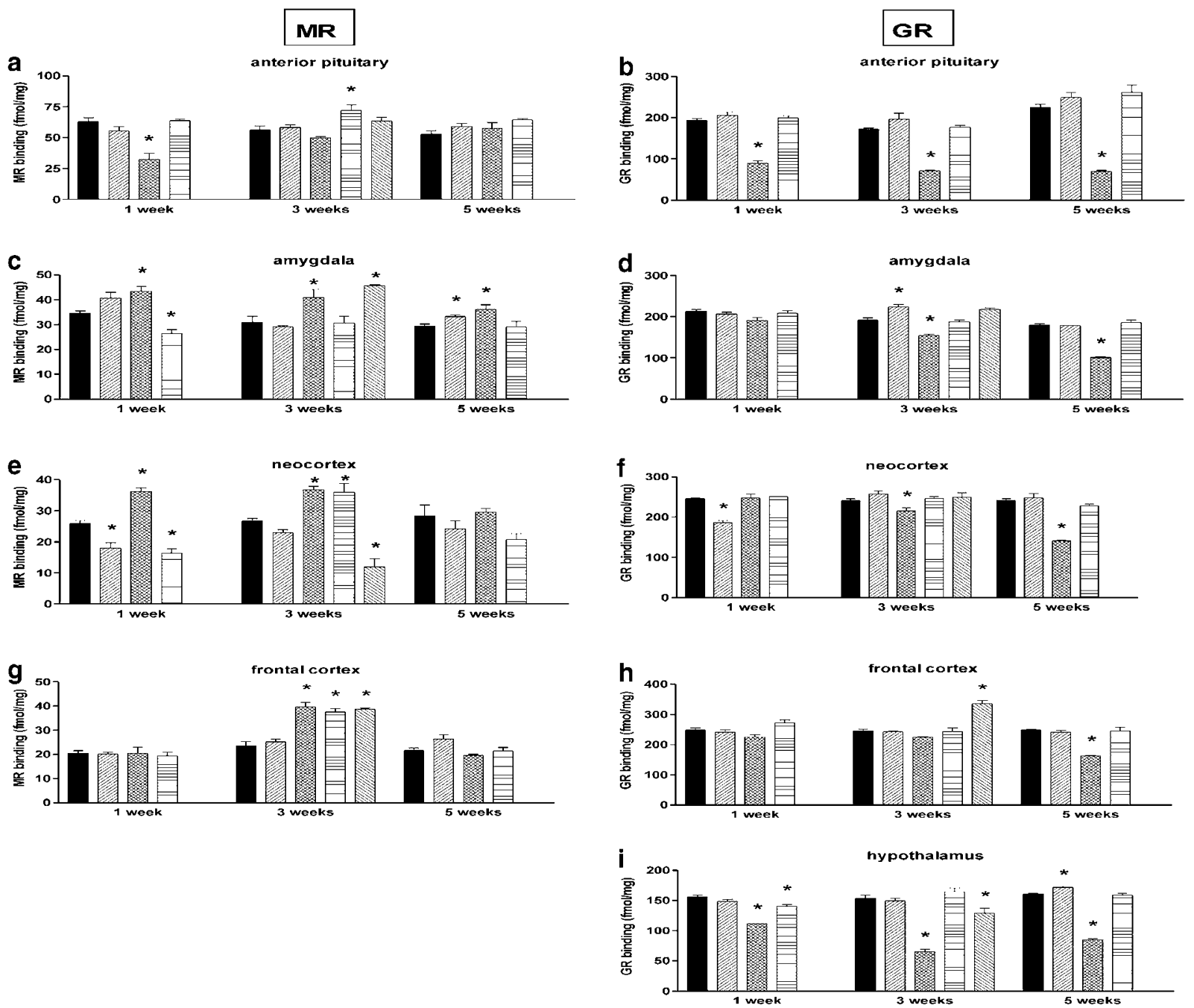

CONTROL

ORg 34850

ORG 34116

ORG 34517

NIS RU 38486

Figure 5 Effect of chronic administration on MR and GR concentration in the anterior pituitary and distinct brain regions. Rats (5-7 per group) received either ORGANON GR antagonists (233 mg substance per $950 \mathrm{~g}$ food) or food only. The rats were killed after 3 weeks of treatment. Adrenalectomy and dissection of brain and pituitary tissues was conducted as described in Materials and methods. Measurements of MR and GR concentrations, expressed as femtomoles per $\mathrm{mg}$ protein (mean \pm SEM), were measured by radioligand binding assay (see Materials and methods). Two-way ANOVA: anterior pituitary$M R$ : effect of duration, $F(2.61)=3.778, p<0.05$; effect of treatment, $F(4.61)=17.279$, $p<0.0005$; effect by interaction of duration and treatment, $F(6.6 I)=6.358, p<0.0005$; GR: effect of duration, $F(2.42)=26.431$, $p<0.0005$; effect of treatment, $F(3.42)=142.433$, $p<0.0005$; effect by interaction of duration and treatment, $F(6.42)=4.816, p<0.01$; hypothalamus-GR: effect of duration, $F(2.52)=7.533$, $p<0.001$; effect of treatment, $F(4.52)=164.815$, $p<0.0005$; effect by interaction of duration and treatment, $F(6.52)=15.645, p<0.0005$, post hoc Dunnett's t-test; * $p<0.05$ (vs the control group).

weight) into adrenalectomized rats showed that ORG 34517 was more potent than the others in occupying GR in the pituitary and various brain areas, while all were unable to occupy MR, clearly underscoring the specificity of the GR antagonists. Furthermore, our findings confirmed results from earlier studies indicating that the 11,21-bisaryl steroids displayed a three-fold lower (ORG 34116) and two-fold lower (ORG 34850) binding affinity to human GR as compared to the 11-monoaryl steroid ORG 34517 (Peeters et al, 1998). Binding of $\left[{ }^{3} \mathrm{H}\right]$ dexamethasone to GR was most significantly reduced in the anterior pituitary, suggesting that penetration of the highly lipophilic GR antagonists was limited by the blood-brain barrier. Hence, the substances may be substrates for the mdrla Pglycoprotein transporter (Cordon-Cardo et al, 1989). In addition, imaging studies have provided evidence for distinct regional differences in cerebral blood flow in rats (Lin et al, 1999) and humans (Schneider et al, 1996), possibly contributing to a region-dependent availability of the substances.

In spite of their strong potency to occupy brain and pituitary GR, chronic oral administration of ORG 34517 and ORG 34850 resulted only in modest changes of GR levels. In contrast, a significantly reduced binding of $\left[{ }^{3} \mathrm{H}\right]$ dexamethasone to brain and pituitary GR of animals chronically treated with ORG 34116 was observed. Different pharmacokinetics of the compounds might account for these different findings, as rats chronically treated with ORG 34116 still had considerably high circulating levels of the compound even $48 \mathrm{~h}$ after administration of the drug had 
a

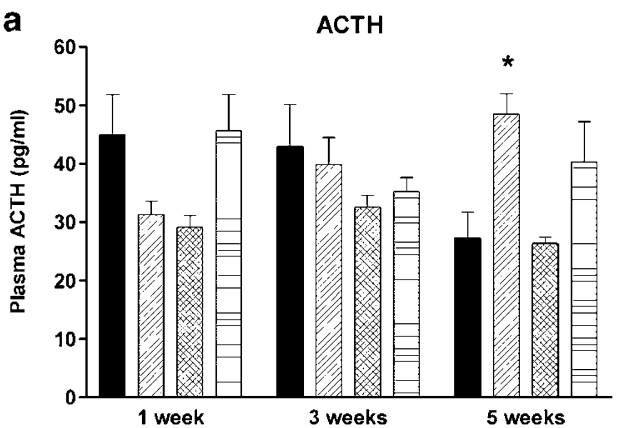

C

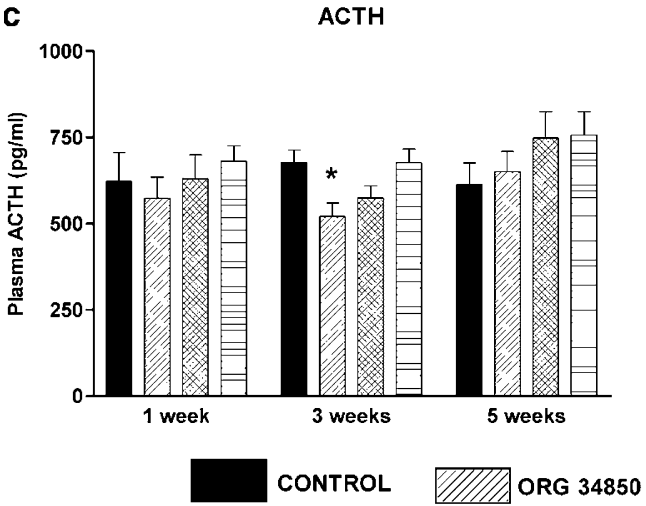

b

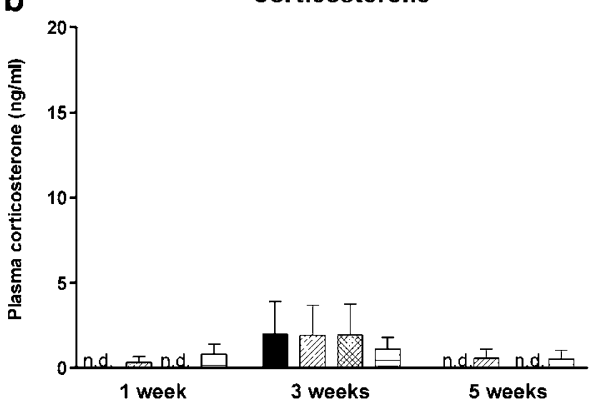

d

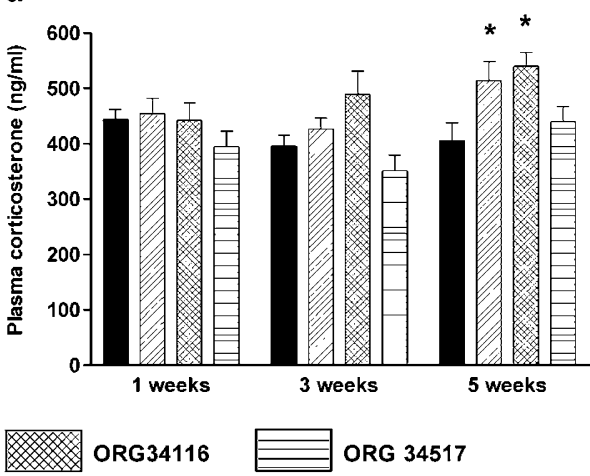

Figure 6 Time course of the effect of GR antagonists on HPA axis activity. Rats (9-15 per group) were treated with GR antagonists (20-25 mg/kg/day) for I, 3, and 5 weeks. The animals were decapitated either under basal morning conditions or after 15 min forced swim stress, as described in Materials and Methods. (a and b) Basal ACTH and corticosterone levels (mean \pm SEM), respectively; (c and d) stress-induced ACTH and corticosterone concentrations (mean $\pm \mathrm{SEM}$ ), respectively. In some cases, basal corticosterone levels were too low to be detected (ND = not detectable). Two-way ANOVA: ACTHbasal: effect of duration, $F(2.60)=0.268, p>0.05$; effect of treatment, $F(3.60)=3.707, p<0.02$; effect by interaction of duration and treatment, $F(6.60)=3.057, p<0.02$; ACTH-poststress: effect of duration, $F(2.96)=3.067, p=0.05$ I; effect of treatment, $F(3.96)=1.464$, $p>0.05$; effect by interaction of duration and treatment, $F(6.96)=0.925, p>0.05$; CORT-poststress: effect of duration, $F(2.95)=4.491$, $p<0.02$; effect of treatment, $F(3.95)=7.024$, $p<0.0005$; effect by interaction of duration and treatment, $F(6.95)=1.357, p>0.05$; post hoc Dunnett's $t$-test; * $p<0.05$ (vs the control group)

been terminated (Dr O Epemolu, NV Organon, Oss, The Netherlands). This in contrast to any of the other compounds. Consequently, GR might still have been occupied by ORG 34116 and therefore unavailable for binding of $\left[{ }^{3} \mathrm{H}\right]$ dexamethasone. The pharmacokinetics of RU 38486 have been extensively studied (Deraedt et al, 1985; Lähteenmaäki et al, 1987): The substance displays extensive binding to $\alpha 1$-acid glycoprotein in humans and to albumin (for a review see Bamberger and Chrousos, 1995; Cadepond et al, 1997), accounting for its long plasma halflife of $20 \mathrm{~h}$. The pharmacokinetics of ORG 34850 and ORG 34116 have not been investigated by the manufacturer. Moreover, no reports describing the pharmacokinetic properties of the selective GR antagonists have been published so far. However, ORG 34517 does not bind to CBG and its $t_{1 / 2}$ in humans is $13-20 \mathrm{~h}$ (BWMM Peeters, personal communication). However, a rapid metabolization and a pronounced first pass effect of ORG 34517 and ORG 34850 could result in only transiently increased GR antagonist levels, but apparently such episodic antagonism seems not sufficient to cause a significant upregulation of GR capacity. Therefore, our results demonstrated that application of GR antagonists does not induce conditions observed after adrenalectomy, which has been shown to upregulate GR levels (Reul et al, 1987).

Even though no significant effects on hippocampal GR capacity could be observed, chronic treatment with ORG
34517 for 3 weeks and bisarylsteroids at almost all time points resulted in significantly increased MR levels in the hippocampus and various other brain areas (cortex, amygdala) via a yet unknown mechanism. Herman and Spencer (1998) demonstrated that the hippocampal GR is subject to heterologous regulation by MR. Reul et al (1987) presented data pointing to a vice versa regulation, as administration of the GR agonist dexamethasone resulted in increased hippocampal MR levels. However, regulation of MR expression in the hippocampus is very complex, involving monoaminergic and serotonergic fibers from various brain regions and growth factors. Gesing et al (2001) showed that CRH increases hippocampal MR expression. In line with our findings, Spencer et al (1998) reported an increase in hippocampal MR levels after administration of the highly selective GR antagonist RU 40555. Furthermore, RU 38486 has been shown to control MR expression via human PR (McDonnell et al, 1994). Previously, Reul et al (unpublished) observed that MR upregulation was triggered by the MR antagonist spironolactone via an intrinsic mechanism, because the effect was seen in adrenalectomized rats. In contrast, the fact that we did not observe any GR upregulation upon GR antagonist binding suggests the absence of such an intrinsic mechanism in GR regulation. Thus, it appears that MR and GR antagonists exert different interactions with their respective receptors. The data of Trapp and Holsboer (1995) indicate 
that binding of an agonist $v s$ an antagonist to MR induces distinct conformational changes, as proteolysis of the antagonist-bound $\mathrm{MR}$ resulted in smaller fragments than proteolysis of the agonist-occupied MR. Correspondingly, Brzozowski et al (1998) and Shiau et al (1998) postulated that the estrogen receptor (ER) antagonists raloxifene and tamoxifen exert their antagonistic properties by inducing a different conformation of the ER ligand binding domain (LBD), and, by that, blocking coactivator binding, resulting in a reduced transactivation capacity. No studies on the molecular effects of specific GR antagonists have been published. Nevertheless, induction of distinct changes in the conformation of GR after binding of the respective GR antagonists could lead to distinct differences in interactions at the genomic level.

The data demonstrate that the studied antagonists had substantial effects on the physical parameters: ORG 34116 and ORG 34850 exerted protective effects on thymus involution, induced by endogenous glucocorticoids, after a treatment period of 1 week and 3 weeks. Interestingly, also long-term treatment with the tricyclic antidepressant amitriptyline has been shown to act protective on thymus involution (Steckler et $a l, 1999$ ), possibly as a result of its dampening effects on glucocorticoid secretion (Reul et al, 1993). In animals treated with the 11,21-bisaryl steroids ORG 34850 and ORG 34116, adrenal weight was enhanced at all time points. This observation points to an enhanced corticotrophic influence during chronic administration, suggesting disinhibition of HPA axis activity in the 11,21bisarylsteroid-treated groups. In contrast, treatment with ORG 34517 did not cause any changes in HPA axis activity, as ORG 34517-treated animals showed no alterations in physical parameters and hormone levels, suggesting a mild antagonistic potency of this compound. Their different GR antagonistic properties of the compounds may be a reflection of the different pharmacological characteristics, that is, metabolism, half-life, and tissue penetration. As mentioned, the pharmacokinetics of ORG 34116 and ORG 34517 have not been investigated, and very limited data have been published on the newly developed compounds so far. Chronic administration of RU 38486 for 3 weeks induced thymus involution, corresponding with its catabolic effect on body weight; both findings are most likely because of the compound's partial GR agonistic properties (Gruol and Altschmied, 1993; Havel et al, 1996). However, no evidence for partial agonism could be found after chronic treatment with the selective GR antagonists.

Our hormone measurements, demonstrating unchanged baseline early morning levels, do not support a disinhibition of the HPA axis during the circadian trough. They correspond with several studies reporting no effect of acute or chronic treatment with RU 38486, administered icv or locally, on basal morning trough ACTH and corticosterone levels (De Kloet et al, 1988; Ratka et al, 1989; Van Haarst et al, 1997), whereas basal corticosterone concentrations during the diurnal peak and after novelty stress were significantly increased (Van Haarst et al, 1996, 1997). These results are in line with the notion that MRs mediate the effects of circadian trough basal levels of corticosteroids, whereas GRs mediate the effects of high glucocorticoid levels during the circadian peak and stress (for a review see De Kloet et al, 1998; Reul et al, 2000). This concept could also elucidate why we did not observe any effects of the specific GR antagonists on basal morning corticosterone levels: During the circadian trough GRs are only poorly occupied by low circulating corticosterone levels (Reul and De Kloet, 1985), and, thus, GR antagonists do not generate 'antagonism', therefore not leading to any alterations in plasma hormone concentrations. Enhanced hippocampal MR concentrations during ongoing GR antagonist treatment could additionally account for a dampening of ACTH and corticosterone secretion during the circadian trough. Moreover, rats consumed most of the antagonists during the night, presumably resulting in higher nocturnal GR antagonist plasma concentrations. Thus, our data suggest that GR antagonism occurred episodically, that is, during the nocturnal peak and stress. These preclinical observations correspond with a clinical study showing HPA axis disinhibition after oral administration of RU 38486 during the morning peak of HPA axis activity in humans (Gaillard et al, 1984). However, several investigations on chronic oral administration of RU 38486 (200 mg/day or $10 \mathrm{mg} / \mathrm{kg}$-day, respectively) to volunteers demonstrated an overall enhanced activity of the HPA axis, reflected by increased circulating plasma ACTH and cortisol concentrations, and enhanced urinary cortisol secretion (Laue et al, 1989; Lamberts et al, 1991).

Furthermore, adrenocortical sensitivity to ACTH shows a characteristic circadian rhythm with a decreased sensitivity to ACTH during the morning trough in rats (Nicholson et al, 1985; Dallman et al, 1987). As we measured the basal hormone levels only in the morning, the obtained low corticosterone levels may also reflect decreased adrenocortical sensitivity to ACTH. If we had measured basal ACTH and corticosterone levels during the secretion peak, we might have obtained increased corticosterone levels despite low ACTH, reflecting increased adrenocortical sensitivity (Van Haarst et al, 1996). However, our findings of increased adrenal weight, corresponding with increased stress-induced corticosterone plasma concentrations after 3 and 5 weeks of chronic ORG 34850 and ORG 34116 administration despite reduced poststress ACTH levels after 3 weeks, suggest that the zona fasciculata of the adrenal gland displayed a gradually enhanced sensitivity to circulating ACTH plasma levels with ongoing chronic treatment in those groups, but not in animals treated with ORG 34517. This notion is consistent with a previous study (Van Haarst et al, 1996) pointing to a shift towards elevated adrenal responsiveness to ACTH after chronic icv infusion of RU $38486(100 \mathrm{ng} / \mathrm{h})$. Moreover, several studies have provided strong evidence that adrenocortical sensitivity is modulated by the autonomic nervous system: Jasper and Engeland (1994) obtained increased ultradian and stress-induced corticosterone plasma concentrations in splanchniectomized animals. Furthermore, Korte et al (1993) demonstrated that blockade of brain $M R$ and GR after icv application of RU 28318 (a selective MR antagonist) and RU 38486, respectively, resulted in an attenuated CRHinduced increase in heart rate and adrenaline plasma concentrations.

We examined the effects of the highly selective GR antagonists ORG 34850, ORG 34116, and ORG 34517 on the rat HPA axis. Several clinical studies point to HPA axis hyperactivity as an important component in the etiology of 
major depression. In this light, the studied selective GR antagonists were developed as a potential therapy for disorders associated with cortisol hypersecretion including major depression. Depressed patients typically show increased HPA acitivity with enhanced CRH drive and a reduced GR feedback (for a review see Holsboer, 2000). Therefore, GR antagonist administration at moderate dosages was preferred to high-dose administration, which could have led to HPA axis disinhibtion. A dose, at which disinhibition would occur, would also be unfavorable to be applied in patients. Overall, chronic oral application of any compound to rats caused a time-dependent enhancement of hippocampal MR capacity, corresponding with our previous observations, which showed an enhanced hippocampal MR capacity during chronic application of different antidepressants to rats (Reul et al, 1993, 1994; Gesing and Reul, in preparation). Moreover, our present finding of significantly increased hippocampal MR capacity after treatment with RU 38486 may correspond with several clinical reports suggesting that treatment with RU 38486 may be effective in psychotic major depression (Van der Lely et al, 1991; Belanoff et al, 2001). Increased hippocampal MR capacity was postulated to be the initial phenomenon in a cascade of successive changes in the HPA axis during the course of a successful antidepressant therapy. However, animals treated with ORG 34116 and ORG 34850 showed increased adrenal weight and elevated poststress corticosterone plasma levels, pointing to - at least episodically - enhanced HPA activity. In contrast, treatment with ORG 34517 did not cause any enhancement in HPA axis activity. In addition to enhancing hippocampal MR capacity, ORG 34517 showed the strongest potency to occupy GR and did not cause any significant changes in HPA activity. Therefore, ORG 34517 might be a promising therapeutic strategy in the treatment of major depression. Indeed, in preliminary clinical trials, this compound has shown antidepressive effects in depressed patients (Peeters, personal communication 2001).

\section{ACKNOWLEDGMENTS}

We thank NV Organon (Oss, The Netherlands) for making their GR antagonists available to us and also Dr BWMM (Ard) Peeters (NV Organon) for providing the structural formulas of the compounds.

\section{REFERENCES}

Bamberger CM, Chrousos GP (1995). The glucocorticoid receptor and RU 486 in man. Ann NY Acad Sci 761: 296-310.

Belanoff KB, Flores BH, Kalezhan M, Sund B, Schatzberg AF (2001). Rapid reversal of psychotic depression using mifepristone. J Clin Psychopharmacol 21: 516-521.

Brady LS, Gold PW, Herkenham M, Lynn AB, Whitfield HJ Jr (1992). The antidepressants fluoxetine, idazoxan and phenelzine alter corticotropin-releasing hormone and tyrosin hydroxylase mRNA levels in rat brain: therapeutic implications. Brain Res 572: 117-125.

Brady LS, Whitfield HJ Jr , Fox RJ, Gold PW, Herkenham M (1991). Long-term antidepressant administration alters corticotropinreleasing hormone, tyrosine hydroxylase, and mineralocorticoid receptor gene expression in rat brain. Therapeutic implications. J Clin Invest 87: 831-837.
Brzozowski AM, Pike ACW, Dauter Z, Hubbard RE, Bonn T, Engstrom O et al (1998). Molecular basis of agonism and antagonism in the estrogen receptor. Nature 389: 753-758.

Cadepond F, Ulmann A, Baulieu EE (1997). RU 486 (mifepristone): mechanism of action and clinical uses. Annu Rev Med 48: 129156.

Cordon-Cardo C, O'Brien JP, Casals D, Rittman-Grauer L, Biedler JL, Melamed MR et al (1989). Multidrug-resistance gene (Pglycoprotein) is expressed by endothelial cells at blood-brain barrier sites. Proc Natl Acad Sci USA 86: 695-698.

Dallman MF, Akana SF, Cascio CS, Darlington DN, Jacobson L, Levin N (1987). Regulation of ACTH secretion: variation on a theme of B. Prog Horm Res 43: 113-173.

De Kloet ER, De Kock S, Schild V, Veldhuis HD (1988). Antiglucocorticoid RU 38486 attenuates retention of a behaviour and disinhibits the hypothalamic-pituitary-adrenal axis at different sites. Neuroendocrinology 47: 109-115.

De Kloet ER, McEwen BS (1976). A putative glucocorticoid receptor and a transcortin-like macromolecule in pituitary cytosol. Biochim Biophys Acta 421: 115-123.

De Kloet ER, Reul JMHM (1987). Feedback action and tonic influence of corticosteroids on brain function: a concept arising from the heterogeneity of brain receptor systems. Psychoneuroendocrinology 12: 83-105.

De Kloet ER, Vreugdenhil E, Oitzl MS, Joels M (1998). Brain corticosteroid receptor balance in health and disease. Endocr Rev 19: 269-301.

De Nicola AF, Tornello S, Weisenberg I, Fridman O, Birmingham MK (1981). Uptake and binding of $3 \mathrm{H}$-aldosterone by the anterior pituitary and brain regions in adrenalectomized rats. Horm Metab Res 13: 103-106.

Deraedt R, Bonnat C, Busigny M (1985). Pharmacokinetics of RU 48. In: Baulieu EE, Segal S (eds). The Antiprogestin Steroid RU 486 and Human Fertility Control. Plenum Press: New York. pp 103-122.

Fuxe K, Wilkström AC, Okret S, Agnati LF, Härfstrand A, Yu ZY et al (1985). Mapping of glucocorticoid receptor immunoreactive neurons in the rat tel- and diencephalon using a monoclonal antibody against rat liver glucocorticoid receptor. Endocrinology 117: 1803-1812.

Gagne D, Pons M, Philibert D (1985). RU 38486: a potent antiglucocorticoid in vitro and in vivo. J Steroid Biochem 23: 247.

Gaillard RC, Riondell A, Muller AF, Herrmann W, Baulieu EE (1984). RU 486: a steroid with antiglucocortcosteroid activity that only disinhibits the human pituitary-adrenal system at a specific time of the day. Proc Natl Acad Sci USA 81: 3879-3882. Gesing A, Bilang-Bleuel A, Droste SK, Linthorst ACE, Holsboer F, Reul JMHM (2001). Psychological stress increases hippocampal mineralocorticoid receptor levels: involvement of corticotropin releasing hormone. J Neurosci 21: 4822-4829.

Gesing A, Reul JMHM (2003). Chronic treatment with antidepressant drugs results in attenuation of hypothalamicpituitary-adrenocortical responses irrespective of their neuropharmacological profile. In preparation.

Gruol DJ, Altschmied J (1993). Synergistic induction of apoptosis with glucocorticoids and $3^{\prime}, 5^{\prime}$-cyclic adenosine monophosphate reveals agonist activity by RU 486. Mol Endocrinol 7: 104-113.

Havel PJ, Busch BL, Curry DL, Johnson PR, Dallman MF, Stern JS (1996). Predominantly glucocorticoid agonist actions of RU 486 in young specific-pathogen-free Zucker rats. Am J Phys 271(Pt 2): R710-R717.

Herman JP, Patel PD, Akil H, Watson SJ (1989). Localization and regulation of glucocorticoid and mineralocorticoid receptor messenger RNAs in the hippocampal formation of the rat. $\mathrm{Mol}$ Endocrinol 3: 1886-1894.

Herman JP, Spencer R (1998). Regulation of hippocampal glucocorticoid receptor gene transcription and protein expression in vivo. J Neurosci 18: 7462-7473. 
Heuser IJ, Wark H-J, Borchardt D, Hermle L (1990). Limbichypothalamic-pituitary-adrenal axis dysfunction in elderly depressed patients. Clin Neuropharmacol 13(Suppl 2): 188-190.

Holsboer F (2000). The corticosteroid receptor hypothesis of depression. Neuropsychopharmacology 23: 477-501.

Holsboer F, Liebl R, Hofschuster E (1982). Repeated dexamethasone suppression test during depressive illness. Normalization of test results compared with clinical improvement. J Affect Dis 4: 93-101.

Holsboer-Trachsler E, Stohler R, Hatzinger M (1991). Repeated administration of the combined dexamethasone/hCRH stimulation test during treatment of depression. Psychiatry Res 38: 163171.

Jasper MS, Engeland WC (1994). Splanchnic neural activity modulates ultradian and circadian rhythms in adrenocortical secretion in awake rats. Neuroendocrinology 59: 97-109.

Kawai S, Nieman LK, Brandon DD, Udelsman R, Loriaux DL, Chrousos GP (1987). Pharmacokinetic properties of the antiglucocorticoid and antiprogesterone RU 486 in man. J Pharmacol Exp Ther 241: 401-406.

Kitayama I, Janson AM, Cintra A, Fuxe K, Agnati LF, gren SO et al (1988). Effects of chronic imipramine treatment on glucocorticoid receptor immunoreactivity in various regions of the rat brain. Evidence for selective increases of glucocorticoid receptor immunoreactivity in the locus coeruleus and in 5-hydroxytryptamine nerve cell groups of the rostral ventromedial medulla. $J$ Neural Trans 73: 191-203.

Korte SM, Bouws GAH, Bohus B (1993). Central actions of corticotropin-releasing hormone on behavioral, neuroendocrine, and cardiovascular regulation: brain corticoid receptor involvement. Horm Behav 27: 167-183.

Lähteenmäki P, Heikinheimo O, Croxatto H, Spitz I, Shoupe D, Birgerson L et al (1987). Pharmacokinetics and metabolism of RU 48. J Steroid Biochem 27: 859-863.

Lamberts SW, Koper JW, de Jong FH (1991). The endocrine effects of long-term treatment with mifepristone (RU 486). J Clin Endocrinol Metab 73: 187-191.

Laue L, Lotze MT, Chrousos GP, Barnes K, Loriaux DL, Fleisher TA (1990). Effect of chronic treatment with the glucocorticoid antagonist RU 486 in man: toxicity, immunological, and hormonal aspects. J Clin Endocrinol Metab 71: 1474-1480.

Lin W, Celik A, Paczynski RP, Hsu CY, Powers WJ (1999). Quantitiative magnetic resonance imaging in experimental hypercapnia: improvement in the relation between changes in brain R2 and the oxygen saturation of venous blood after correction for changes in cerebral volume. J Cereb Blood Flow Metab 19: 853-862.

Linkowski P, Mendlewicz J, Leclerq R, Brasseur M, Hubain P, Goldstein J et al (1985). The 24-hour profile of adrenocorticotrophin and cortisol in major depressive illness. J Clin Endocrinol Metab 61: 429-438.

Lowry OH, Rosebrough NJ, Farr AL, Randall NJ (1951). Protein measurements with the Folin phenol reagent. J Biol Chem 193: 265-275.

McDonnell DP, Shahbahz MM, Vegeto E, Goldman ME (1994). The human progesterone receptor A-form functions as a transcriptional modulator of mineralocorticoid receptor transcriptional activity. J Steroid Biochem Mol Biol 48: 425-432.

Gerlach JL, McEwen BS (1972). Rat brain binds adrenal steroid hormone: radioautography of hippocampus with corticosterone. Science 175: 1133-1136.

Moguilewsky M, Raynaud JP (1980). Evidence for specific mineralocorticoid receptor in rat pituitary and brain. J Steroid Biochem 12: 309-314.

Mortola JF, Liu JH, Gillin JC, Rasmussen DD, Yen SSC (1987). Pulsatile rhythms of adrenocorticotropin (ACTH) and cortisol in women with endogenous depression: evidence for increased ACTH pulse frequency. J Clin Endocrinol Metab 65: 962-968.
Murphy BE, Ghadirian AM, Dhar V (1998). Neuroendocrine responses in patients to inhibitors of steroid biosynthesis in patients with major depression resistant to antidepressant therapy. Can J Psychiatry 43: 279-286.

Nicholson S, Lin JH, Mahmoud S, Campbell E, Gillham B, Jones M (1985). Diurnal variation in responsiveness of the hypothalamopituitary-adrenocortical axis of the rat. Neuroendocrinology 40: 217-224.

Peeters BW, Tonnaer JA, Groen MB, Broekkamp CL, van der Voort HA, Schoonen WG et al (1998). Glucocrticoid receptor antagonists: new tools to investigate disorders characterized by cortisol hypersecretion. printed by NV Organon, Oss, The Netherlands.

Porsolt RD, Anton G, Blavat N, Jalfre M (1978). Behavioural despair in rats: a new model sensitive to antidepressant treatments. Eur J Pharmacol 47: 379-391.

Ratka A, Sutanto W, Bloemers M, De Kloet ER (1989). On the role of brain mineralocorticoid (Type I) and glucocorticoid (Type II) receptors in neuroendocrine regulations. Neuroendocrinology 50: $117-123$.

Rees HD, Stumpf WE, Sar M, Petrusz P (1977). Autoradiographic studies of $3 \mathrm{H}$-dexamethasone uptake in immunocytochemically characterized cells of the rat pituitary. Cell Tissue Res 182: 347356.

Reul JMHM, De Kloet ER (1985). Two receptor systems for corticosterone in rat brain: microdistribution and differential occupation. Endocrinology 117: 2505-2512.

Reul JMHM, De Kloet ER (1986). Anatomical resolution of two types of corticosterone receptor sites in rat brain with in vivo autoradiography and computerized image analysis. J Steroid Biochem 24: 269-272.

Reul JMHM, de Kloet ER, van Sluys FJ, Rijnberg A, Rothuizen J (1990). Binding characteristics of mineralocorticoid and glucocorticoid receptors in dog brain and pituitary. Endocrinology 127: 907-915.

Reul JMHM, Gesing A, Droste S, Stec ISM, Weber A, Bachmann C et al (2000). The brain mineralocorticoid receptor: greedy for ligand, mysterious in function. Eur $J$ Pharmacol 405: 235-249.

Reul JMHM, Labeur MS, Grigoriadis DE, De Souza EB, Holsboer F (1994). Hypothalamic-pituitary-adrenocortical axis changes in the rat after long-term treatment with the reversible monoamine oxidase-A inhibitor moclobemide. Neuroendocrinology 60: 509_ 519.

Reul JMHM, Pearce PT, Funder JW, Krozowski ZS (1989). Type I and Type II corticosteroid receptor gene expression in the rat: effect of adrenalectomy and dexamethasone administration. Mol Endocrinol 3: 1674-1680.

Reul JMHM, Stec I, Söder M, Holsboer F (1993). Chronic treatment of rats with the antidepressant amitriptyline attenuates the activity of the hypothalamic-pituitary-adrenocortical system. Endocrinology 133: 312-320.

Reul JMHM, van den Bosch FR, De Kloet ER (1987). Differential response of type I and type II corticosteroid receptor to changes in plasma steroid level and circadian rhythmicity. Neuroendocrinology 45: 407-412.

Reus VI, Wolkowitz OM (2001). Antiglucocorticoid drugs in the treatment of depression. Expert Opin Invest Drugs 10: 17891796.

Sachar EJ, Hellman L, Roffwarg HP, Halpern FS, Fukushima DK, Gallagher TF (1973). Disrupted 24-hr patterns of cortisol secretion in psychotic depression. Arch Gen Psychiatry 28: 19-24.

Schneider F, Gur RE, Alavi A, Seligman ME, Harper Mozley L, Smith RJ et al (1996). Cerebral blood flow changes in limbic regions induced by unsolvable anagram tasks. Am J Psychiatry 153: 206-212.

Shiau AK, Barstad D, Loria PM, Cheng L, Kushner PJ, Agard DA et al (1998). The structural basis of estrogen/coactivator recogni- 
tion and the antagonism of this interaction by tamoxifen. Cell 95: 927-937.

Spencer RL, Kim PJ, Kalman BA, Cole MA (1998). Evidence for mineralocorticoid receptor facilitation of glucocorticoid receptor-dependent regulation of hypothalamic-pituitary-adrenal axis activity. Endocrinology 139: 2718-2727.

Steckler T, Holsboer F, Reul JMHM (1999). Glucocorticoids and depression. Balli 13: 107-124.

Trapp T, Holsboer F (1995). Ligand-induced conformational changes in the mineralocorticoid receptor analyzed by protease mapping. Biochem Biophys Res Commun 215: 286-291.

Van der Lely A, Foeken K, Van der Mast RC, Lamberts SW (1991). Rapid reversal of acute psychosis in the Cushing syndrome with the cortisol-receptor antagonist mifepristone (RU 486). Ann Intern Med 114: 143-144.
Van Eekelen JAM, Jiang W, De Kloet ER, Bohn MC (1988). Distribution of the mineralocorticoid and the glucocorticoid receptor mRNAs in the rat hippocampus. J Neurosci Res 21: 88-94.

Van Haarst AD, Oitzl MS, De Kloet ER (1997). Facilitation of feedback inhibition through blockade of glucocorticoid receptors in the hippocampus. Neurchem Res 22: 1323-1328.

Van Haarst AD, Oitzl MS, Workel JO, de Kloet ER (1996). Chronic brain glucocorticoid receptor blockade enhances the rise in circadian and stress-induced pituitary-adrenal activity. Endocrinology 137: 4935-4943.

Wolkowitz OM, Reus VI, Chan T, Manfredi F, Raum W, Johnson R et al (1999). Antiglucocorticoid treatment of depression: doubleblind ketoconazole. Biol Psychiatry 45: 1070-1074. 